\title{
Patterns of Illicit Drug Use and Opioid Abuse in Patients with Chronic Pain at Initial Evaluation: A Prospective, Observational Study
}

\author{
Laxmaiah Manchikanti, MD, Kim S. Damron, RN, Carla D. McManus, RN, BSN, and Renee C. Barnhill, RN
}

Background: Over the years, there has been a shift toward the increased reliance on opioids for the treatment of chronic pain. It is well known that some patients do not provide an appropriate history or underestimate their drug intake, and may exaggerate reported pain levels. Numerous studies have documented the incidence of illicit drug use and abuse of opioids in chronic pain patients. It is not known what proportion of patients have already been exposed to controlled substances prior to presenting for interventional pain management.

Objective: To evaluate and identify the prevalence of controlled substance use, demographic characteristics, and psychological characteristics of patients presenting for in- terventional pain management along with illicit drug use.

Study Design: A prospective, observational study.

Methods: A total of 100 patients pre senting at an interventional pain management setting for initial evaluation were evaluated by detailed history and urine drug testing for controlled substance use and illicit drug use.

Results: Duration of pain on average was 9.3 years, $57 \%$ of the patients had involvement of more than one body region, $90 \%$ were taking opioids, $47 \%$ had been seen by 5 or more providers, and more than $70 \%$ presented with psychological problems.
Twenty-three patients tested positive for illicit drugs and 12 patients were positive for opioids even though they had no prescription and denied taking opioids. Twentyseven patients either under-reported (16) or over-reported (11) opioid use.

Conclusion: Ninety percent of these patients were taking opioids. Twenty-seven patients incorrectly reported opioid use, either underuse or overuse, with 23 patients using illicit drugs, 12 using non-prescription opioids, and with 35 of 100 patients at initial evaluation exhibiting one of the abuse behaviors.

Keywords: Illicit drug use, controlled substance abuse, abuse, misuse, drug dependence
Chronic pain is an important and common public health problem, not only in the United States, but across the world (1-10). Verhaak et al (1), following the review of 15 epidemiological studies, concluded that in the adult population, chronic pain ranges from $2 \%$ to $40 \%$, with a median point prevalence of $15 \%$. Van Den Kerhof et al (2) reaffirmed the overall prevalence of chronic pain as $15 \%$. Moulin et al (3) reported on the chronic and resistant nature of chronic pain with an average duration of pain of 10.7 years.

From Pain Management Center of Paducah, Paducah, Kentucky

Address Correspondence: Laxmaiah Manchikanti, MD, 2831 Lone Oak Road, Paducah, Kentucky 42003

Funding: Facilities and suplies were provided by Ambulatory Surgery Center and Pain Management Center of Paducah, Paducah, KY 42003

Disclaimer: There was no external funding in preparation of this manuscript.

Conflict of Interest: None

Acknowledgement:

Manuscript received on $7 / 07 / 04$

Revision submitted on 9/07/04

Accepted for publication on 9/23/04
Elliott et al (4) showed low recovery rates for chronic pain. Yeung et al (5) showed that musculoskeletal symptoms for multiple body regions ( 2 or more) were more prevalent (64\%) among workers than those for single body regions, which involved only $19 \%$ of workers.

Due to the inability to provide most chronic pain patients with a precise pathoanatomic diagnosis, a multitude of pharmacologic agents are commonly used for symptom relief. Opioids, are the most potent and effective analgesics available, and are one of the most widely prescribed and abused medications for chronic pain. In addition, the non-medical use of prescription drugs is a serious public health concern. Non-medical use of prescription drugs like opioids, central nervous system depressants and stimulants can lead to addiction, misuse, and diversion. Thus, some physicians are reluctant to prescribe opioids on a long-term basis for chronic pain due to concerns over the serious side effects of opioids including respiratory depression, constipation, nausea, cognitive impairment, peripheral edema, and hypogonadism; the development of drug tolerance, which may lead to increase in drug dosage over time with loss of control; and the risk of physical dependence, addiction, abuse, misuse, and diversion. Further, the effectiveness of the longterm use of opioids in chronic pain is not supported in the literature and physicians are concerned about legal implications with abuse, misuse, diversion, and investigation by authorities. United States, constituting of $4.6 \%$ of World's population, consumrs a whopping $80 \%$ of opioids.

However, proponents of the use of opioids for chronic pain of non-cancer origin continue to profess that under-treatment of pain is a major public health issue in the United States (1113). Thus far, the effectiveness of opioids in chronic pain management on a long-term basis has not been convincingly demonstrated (14). Luo et al (15) showed that the frequency of overall opioid use among individuals with back pain was approximately $12 \%$. Turk et 
al $(16,17)$ found that rheumatologists, family practitioners, and internists were much more likely to prescribe opioids for chronic pain than surgeons and neurologists. In pain management settings, over $90 \%$ of patients receive opioids for chronic pain management (18-27). Consequently, there may be abuse and misuse of controlled substances, as well as illicit drug use in interventional pain management settings managing chronic pain (18-27).

Recently, pain management physicians have been blamed for deaths related to controlled substances and for their prescribing patterns. It has been reported that almost half a ton of prescription narcotics reached six counties in Eastern Kentucky from 1999 to 2001, equating to 0.75 lbs. for every adult in those counties (28). In addition, it was reported that on a per capita basis, Eastern Kentucky drugstores, hospitals, and legal outlets received more prescription pain killers than anywhere else in the United States. Further, three Eastern Kentucky counties had enough Lortab, Lorcet, and Vicodin pills in 2001 to provide every adult in those counties with 156 pills (28).

Nationally, deaths related to controlled substances including methadone and OxyContin have been increasing at a speed unimaginable to most physicians. Consequently, pain physicians on a daily basis must consider litigation for failure to treat pain, litigation for undertreatment, and the possibility of criminal charges for abuse, addiction, or death. In addition, each physician has to understand numerous federal regulations, regulations of the state boards, DEA, State Bureau of Narcotics, and State Boards of Pharmacy.

The Substance Abuse and Mental Health Services Administration, Office of Applied Studies, in a National Survey of Substance Abuse Treatment Services reported use of psychotherapeutic drugs for non-medical purposes in 6.2 million patients in 2002, second only to marijuana (29). This study also reported OxyContin $^{\circledR}$ use for non-medical purposes in approximately 2 million persons in 2002, similar to cocaine use. Consequently, guidelines and techniques for behavioral and adherence monitoring have been developed (19, 30-36).

It is difficult for pain physicians who are caught between the inability to refuse controlled substances and the pressure to reduce the dosage or eliminate the use of these drugs. Chabal et al $(37,38)$ outlined a novel approach that includes the use of opioids as part of a program that provide psychosocial support in a managed care environment. However, this may not be applicable in the interventional pain management setting.

Another problem relates to the philosophy of pseudoaddiction, which is a clinical label without specific therapeutic, predictive, or diagnostic value. Active treatment of pseudoaddiction is also potentially harmful if it results in the medicalization of dysfunctional behavior that fuels somatization and iatrogenesis.

Thus, in chronic pain patients, the use of illicit drugs and opioid misuse or abuse in chronic pain management continues to be a major issue. A significant proportion of patients do not provide an appropriate history or they underestimate their drug intake, while at the same time overestimating their pain levels. At the opposite end of the spectrum, some patients also provide a history of the use of higher doses of opioids prior to presenting for initial evaluation and insist on the continuation of these higher doses or at least the same doses and/or stronger opioids. However, there are no studies in the literature evaluating illicit drug use and opioid drug abuse in patients with chronic pain presenting to pain management centers.

This prospective study was undertaken to document patterns of controlled substance and illicit drug usage among chronic pain patients presenting for initial evaluation, evaluating both physical and psychological factors.

\section{Methods}

A total of 100 consecutive patients, presenting with chronic pain to an interventional pain management practice were evaluated. All patients were evaluated with history, physical examination, psychological evaluation, review of records, and urine drug testing, as an integral part of a comprehensive evaluation provided to the majority of patients presenting to this organization. No financial or other incentive was provided.

\section{Informed Consent}

All patients were given an explanation of the purpose of the study and an opportunity for discussion. They were also advised of the consequences of the drug testing as they may or may not re- ceive subsequent prescriptions based on the results of the drug test. Informed consent was then obtained. Appropriate precautions were taken to protect the privacy and anonymity of all the patients participating in the study.

\section{Inclusion and Exclusion Criteria}

Inclusion criteria included chronic pain of at least 2 year's duration, patients over 18 years of age, and patients who were able to provide voluntary written informed consent to participate in this evaluation.

Exclusion criteria included inability to understand the consent, and patients unwilling to participate in the evaluation.

\section{Evaluation}

The psychological status of each patient was evaluated by psychological history using a DSM-IV ${ }^{\circledR}$ criteria-based questionnaire for depression and anxiety; by the administration of the Millon Clinical Multiaxial Inventory (MCMI-III ${ }^{\circledR}$ ); Pain Patient Profile (P- $\left.3^{\circledR}\right)$ evaluating depression, anxiety, and somatization; and the presence of anti-depressant or anxiolytic medication or therapy. MCMI is a commonly used test delineating the psychological involvement in various medical syndromes. The MCMI-III is the latest version, which evaluates personality disorders and various clinical syndromes including generalized anxiety disorder, depression, and somatoform disorder. The MCMI consists of 175 questions and does not require a psychologist's presence for administration and can be administered in outpatient settings in interventional practices (40).

The Pain Patient Profile (P-3) is a clinically effective instrument for briefly assessing psychological characteristics that are known to affect pain perception and treatment response of patients' in pain. The P-3 consists of 34 items, evaluating depression, anxiety, and somatization. A computerized profile is produced with an interpretation that compares the pain patient to a national sample of patients in pain. Patient responses also are compared to those of a large community sample of "non-patients." The P-3 offers several advantages to pain professionals as its format and content are simple. It can be administered in approximately 15 minutes as part of an initial clinical evaluation, and can be re-administered throughout treatment to measure clini- 
cal progress (41).

A series of questions based on DSMIV criteria were incorporated into the comprehensive pain management questionnaire.

Drug history was obtained from the patient, review of the previous records, and information derived from inquiries of pharmacies and physicians.

\section{Drug Screening}

Rapid Drug Screen was performed on all the patients participating in the study. It is a one-step, lateral flow immunoassay for the simultaneous detection of up to 9 drugs by urinanalysis.

\section{Criteria}

A patient was considered to have major depression if positive on MCMI-III, Pain Patient Profile (P-3), DSM-IV-based questionnaire, or was receiving anti-depressant doses of any of the anti-depressants, after the diagnosis of depression by a primary care physician or a mental health professional. Patients were considered positive for generalized anxiety disorder based on the diagnosis of P-3 Profile, MCMI-III, or DMS-IV-based questionnaire, or if they were receiving anxiolytics for anxiety.

Patients were considered to have somatization disorder if they were positive on either P-3 or MCMI-III.

Drug abuse or misuse was considered if a patient tested positive for a nonprescribed opioid. Potential misuse was considered if the prescribed drug was not detected in urine testing. Positive drug screen for cocaine was considered definitive by Rapid Drug Screen ${ }^{\circledR}$. Positive methamphetamine, amphetamine, or marijuana (THC) were checked for false-positives with a follow-up laboratory evaluation, and evaluation of the history of drugs which caused the false-positive results. The Positive results confirmed by laboratory evaluation were considered as positive.

\section{Statistical Methods}

Differences in proportions were tested using Chi-Squared test. Results were considered statistically significant if the $P$ value was less than 0.05 . The prevalence and $95 \%$ confidence intervals (CI) were calculated.

\section{RESULTS}

Table 1. Demographic characteristics

\begin{tabular}{|c|c|c|}
\hline \multirow{2}{*}{ Gender } & Male & $47 \%$ \\
\hline & Female & $53 \%$ \\
\hline \multirow{3}{*}{ Age } & Range & $19-81$ \\
\hline & $>65$ years & $13 \%$ \\
\hline & Mean \pm SD & $47 \pm 14 \cdot 3$ \\
\hline Weight (lbs.) & Mean \pm SD & $194 \pm 53.8$ \\
\hline Height (inches) & Mean \pm SD & $67.8 \pm 3.9$ \\
\hline \multirow{2}{*}{$\begin{array}{l}\text { Mode of Onset of } \\
\text { the Pain }\end{array}$} & Non-traumatic & $47 \%$ \\
\hline & Traumatic & $53 \%$ \\
\hline \multirow{2}{*}{$\begin{array}{l}\text { Duration of Pain } \\
\text { (years) }\end{array}$} & Range & $2-50$ \\
\hline & Mean \pm SD & $9.3 \pm 9.6$ \\
\hline \multirow{5}{*}{$\begin{array}{l}\text { Employment } \\
\text { Status }\end{array}$} & Employed & $24 \%$ \\
\hline & Unemployed & $18 \%$ \\
\hline & Housewife & $4 \%$ \\
\hline & Over 65 yrs & $11 \%$ \\
\hline & Disabled & $43 \%$ \\
\hline \multicolumn{3}{|c|}{ Number of provider(s) seen } \\
\hline 1 & \multicolumn{2}{|r|}{10} \\
\hline 2 & \multicolumn{2}{|r|}{14} \\
\hline 3 & \multicolumn{2}{|r|}{16} \\
\hline 4 & \multicolumn{2}{|r|}{13} \\
\hline$>5$ & \multicolumn{2}{|r|}{47} \\
\hline Mean \pm SD & \multicolumn{2}{|r|}{$4 \pm 1.8$} \\
\hline
\end{tabular}

\section{Table 2. Illustration of pain characteristics}

\begin{tabular}{|l|c|}
\hline Primary Pain Site \\
\hline Lumbar Spine & $63 \%$ \\
\hline Cervical Spine & $23 \%$ \\
\hline Thoracic spine & $6 \%$ \\
\hline Other & $8 \%$ \\
\hline
\end{tabular}

\section{Number of pain problems}

\begin{tabular}{|l|l|}
\hline 1 region & $43 \%$ \\
\hline 2 regions & $36 \%$ \\
\hline$>3$ regions & $21 \%$ \\
\hline
\end{tabular}

\section{Average pain levels on numeric scale}

\begin{tabular}{|l|c|}
\hline$<5$ & 0 \\
\hline 5 & 10 \\
\hline 6 & 11 \\
\hline 7 & 14 \\
\hline 8 & 35 \\
\hline 9 & 14 \\
\hline 10 & 16 \\
\hline Mean $\mathbf{S D}$ & $\mathbf{7 . 8} \mathbf{1 . 5}$ \\
\hline
\end{tabular}

Patient Flow

From January 2003 to June 2003, a total of 142 new patients with chron- ic pain were evaluated. Of these, 132 patients were eligible to participate in the study. Inclusion criteria were not met by 
Table 3. Psychological Status

\begin{tabular}{|l|c|c|c|}
\hline & Depression & Anxiety & Somatization \\
\hline Positive P3 profile & $17 \%$ & $16 \%$ & $16 \%$ \\
\hline Positive MCMI-III & $17 \%$ & $33 \%$ & $16 \%$ \\
\hline Questionnaire & $64 \%$ & $64 \%$ & - \\
\hline $\begin{array}{l}\text { Anti- Depressant and/or } \\
\text { Anxiolytic Therapy }\end{array}$ & $37 \%$ & $21 \%$ & - \\
\hline Total* & $73 \%$ & $68 \%$ & $26 \%$ \\
\hline
\end{tabular}

*Totals may not equal $100 \%$, as patients may have been positive in multiple categories.

Table 4. Controlled substance use

\begin{tabular}{|l|c|c|c|c|c|c|}
\hline & $\begin{array}{c}\text { Patient } \\
\text { History }\end{array}$ & $\begin{array}{c}\text { Based } \\
\text { on Other } \\
\text { Sources }\end{array}$ & $\begin{array}{c}\text { Positive Testing } \\
\text { Without History } \\
\text { of Prescription }\end{array}$ & Total & $\begin{array}{c}\text { Under } \\
\text { Reporting }\end{array}$ & $\begin{array}{c}\text { Over } \\
\text { Reporting }\end{array}$ \\
\hline Opioid(s) & 62 & 16 & 12 & $90^{*}$ & 16 & 11 \\
\hline Benzodiazepine(s) & 26 & 12 & 4 & $42^{*}$ & 8 & 6 \\
\hline
\end{tabular}

* Indicates significant difference than admitted use by the patient history $p<0.05$

18 patients, whereas 14 patients refused to participate or were unable to provide a urine specimen.

\section{Demographic Characteristics}

As illustrated in Table 1, patients were predominantly female and younger than 65 years of age. Fifty-three percent of the patients provided a history of pain onset following an incident. Duration of pain ranged from 2 to 50 years with a mean of 9.3 years. Forty-three percent of the patients were disabled. Thirteen percent were retired. Of the $100 \mathrm{pa}$ tients evaluated, $24 \%$ were employed and $18 \%$ were actively seeking employment. The remaining $58 \%$ of the patients were not seeking any type of employment. The average number of providers seen previously for pain was 4 , and $60 \%$ of the patients had been seen by 4 or more providers. Seventy-six patients were seen by at least 3 providers.

\section{Pain Characteristics}

Pain characteristics are illustrated in Table 2. The primary pain site was the lumbar spine $(63 \%)$ followed by the cervical spine $(23 \%)$. The proportion of patients with multiple pain problems was $57 \%$. The average pain level was 6 or greater on a scale of 0 to 10 in $90 \%$ of the patients.

\section{Psychological Status}

Depression was identified in $73 \%$ of the patients, anxiety in $68 \%$, and somatization in $26 \%$.

Table 4 illustrates controlled substance use in 100 patients. There was a large variance between the history provided by the patient and the subsequent information obtained on these patients regarding the use of controlled substances. Eleven of 62 patients provided higher intake than actual use and requested higher dosages and/or stronger controlled substances, while 16 patients underreported their use. Only 30 of the 90 patients taking opioids or benzodiazepines reported accurate use. Total use of opioids and benzodiazepines was significantly higher ( 90 versus 62 and 42 versus 26 ) than admitted use. $\mathrm{Cl}=$ Confidence Intervals

\section{Illicit Drug Use}

Thirty-one patients admitted to illicit drug use in the past, whereas 19 admitted to current use of illicit drugs. In contrast, 23 of the patients tested positive for illicit drugs in their urine at the time of the evaluation (Table 5). In addition, 12 of the patients were positive for opioids without a prescription despite a denial of taking opioids (Table $6)$. Only 36 of the patients tested positive for prescribed opioids with 42 of the patients receiving opioids with no substance detected in their urine. Thus, it is conceivable that, potentially, up to $77 \%$ may have misresented their drug use.

\section{Correlation with Other Factors}

Due to the small number of patients in subcategories, there were no correlations detected with psychological status or employment status.

\section{Discussion}

This prospective evaluation of demographic characteristics and drug usage patterns in patients with chronic pain of at least 2 years of duration presenting to an interventional pain management practice illustrated that a total of 90 of the 100 patients were using opioids, with 78 using officially, and 12 without a prescription. This was in contrast to the history where only 62 patients admitted to using opioids, and 28 patients provided an inaccurate history. Similar results were found with benzodiazepines. Further, 23 pa-

Table 5. Prevalence of illicit drug use
\begin{tabular}{|l|c|}
\hline & Drug test positive \\
\hline Cocaine & $4 \%(95 \% \mathrm{Cl}, 0 \%-8 \%)$ \\
\hline Marijuana (THC) & $19 \%(95 \% \mathrm{Cl}, 11 \%-27 \%)$ \\
\hline Amphetamine/Methamphetamine & $2 \%(95 \% \mathrm{Cl}, 0 \%-7 \%)$ \\
\hline Totals* & $23 \%(95 \% \mathrm{Cl}, 14 \%-32 \%)$ \\
\hline
\end{tabular}

*Totals may not correlate as some patients were positive in multiple categories

Table 6. Combined use of illicit drugs and opioids and misuse of opioids

\begin{tabular}{|l|l|}
\hline Illicit drug use & 23 \\
\hline Non-prescription opioid use & 12 \\
\hline Absent opioid with opioid prescription & 42 \\
\hline Total abuse* $^{\star}$ & 35 \\
\hline Potential or Possible Total Inappropriate Use* $^{*}$ & $\mathbf{7 7}$ \\
\hline
\end{tabular}

*Totals may not correlate as some patients were positive or included in multiple categories 
tients tested positive for illicit drugs. This prevalence was higher than the prevalence of illicit drug use in patients without controlled substance abuse in interventional pain management as previously described as $16 \%(22)$.

Patients presenting to this interventional pain management center suffered for a long time, with a median duration of pain of 9.3 years. Forty-three percent were on disability, $67 \%$ under 65 years of age, and only $24 \%$ were employed. Further, 57 of the patients presented with more than one pain problem, 90 patients presented with an average numeric pain scale of 6 or higher, and 47 visited 5 or more providers and 86 at least 3 providers. Sixteen patients reported or provided incorrect history of opioid intake. Eleven patients overreported their opioid intake and 16 patients underreporting their use. In addition, 23 patients were taking illicit drugs, 12 were using non-prescription opioids, with a total of 35 patients exhibiting one or more abuse behaviors.

Thus, interventional pain management physicians are faced with patients providing inappropriate histories of opioid use, and a significant proportion of patients have been exposed to opioids and other controlled substances. Moreover, the physician needs to identify the structural basis of chronic pain and attempt to modify patient behaviors with the aim of improving functional status, reducing pain, and returning patients to work whenever feasible. These findings suggest the necessity of monitoring of opioid usage by their patients. Physicians should be aware of the possibilities of doctor shopping, misuse, lack of compliance, and illicit drug use.

However, there continues to be a shift toward the increased reliance on opioids for the treatment of chronic pain with or without other treatment. The media and pharmaceutical companies have helped to promote the reliance on opioids in unlimited dosages by focusing on anecdotal patient experiences and by highlighting "heroic" physicians who have been "victimized" because of opioid prescribing patterns $(37,39)$. This was also fueled by professional societies who, in the name of advocacy and appropriate patient management, have applied lesion learned from acute and cancer pain therapy to the domain of chronic pain. Chabal et al $(37,39)$ opine that because opioids reduce pain for most patients for at least a short while, opioids offer a seductively simple method to treat nociception. Further, they stated that experience shows that although some patients seem to do well on almost homeopathic doses of opioids, there are still many patients who are not satisfied even with much larger doses of opioids. Thus, patients may be dissatisfied not only on low doses but also on robust doses and yet may not get any significant relief. Chabal et al $(37,39)$ suggest that for a provider compelled to help and a patient desperate for help, opioids offer an easy yet irrational treatment that medicalizes a whole host of ills.

Chabal et al $(37,38)$ further suggest that, "we should pause in our glamorous media-fueled exuberance over new opioids and new methods of delivery to consider the lessons from history and ask whether we are helping some patients but harming others. Most reports laud the virtues of the individual cases but neglect those who demand ever-increasing doses of opioids or those who suffer from side effects."

Among all the illicit drugs used in the United States, marijuana has been the most common illicit substance used for several decades $(29,42,43)$. Marijuana use is associated with impaired educational attainment (44), reduced workplace productivity (45), and increased risk for abuse of other substances (46). Marijuana use has been shown to play a major role in motor vehicle crashes (47) and to cause adverse effects on cardiovascular and respiratory systems $(48,49)$. The use of marijuana or hashish produces feelings of relaxation and well-being and impairs cognitive function and performance of psychomotor tasks (50). While overdose can induce panic attack and psychosis (51), symptoms of withdrawal include restlessness, irritability, and insomnia (52). Associations between early cannabis use and later drug use and abuse/dependence have been demonstrated, which may arise from the effects of the peer and social context within which cannabis is used and obtained (46). At least one-third of the US population has used marijuana sometime in their lives. The drug is considered a "gateway" to the world of illicit drug abuse. Various reasons attributed to its widespread use are: relaxed public perception of the harm; popularization by the media and by groups advocating legalization; the internet; and the trend of smoking marijuana filled cigars. In this study, marijuana was detected in $19 \%$ (95\% CI, $11 \%$ to $27 \%$ ) of patients, the most commonly abused illicit drug in our study.

Cocaine is a potent blocker of dopamine-, norepinephrine-, and serotoninuptake transporters (50). It is available as white crystalline powder or crack or rock cocaine. Cocaine is the second most commonly used illicit drug in the United States. Cocaine is a powerful addictive drug (53). Smoking crack can cause severe chest pains with lung trauma and bleeding (53). The mixing of cocaine and alcohol increases the rate of sudden death (53) and cocaine-related deaths are often a result of cardiac arrest or seizures followed by respiratory arrest (53). The current study showed cocaine use in $4 \%$ (95\% CI, $0 \%$ to $8 \%$ ).

Amphetamine and methamphetamine are also known as meth, poor man's cocaine, crystal meth, ice, glass, etc. Short-term administration of amphetamine and methamphetamine produces euphoria, a feeling of well-being, and alertness, as well as increased arousal, concentration, and motor activity. They increase blood pressure and the pulse rate and induce the release of corticotrophinreleasing factor, corticotrophin, and cortisol $(54,55)$. However, long-term use may cause irritability, aggressive, and stereotyped behavior, and paranoid-like psychosis (50). Craving for amphetamine and methamphetamine is very intense even though clinical signs of withdrawal can be mild (56). Serious consequences may be associated with acute intoxication with cerebral hemorrhage, hyperthermia, heat stroke, the serotonin syndrome, panic, and psychosis (50). The serotonin syndrome is characterized by altered mental status, autonomic irritability, and neuromuscular abnormalities resulting in hyperthermia (44). Other withdrawal symptoms may include depression, anxiety, fatigue, violent behavior, insomnia, confusion, auditory hallucinations, delusions, with chronic use, and damage to the brain similar to Alzheimer's disease and epilepsy (57). Amphetamine and methamphetamines were seen in $2 \%(95 \%$ CI, $0 \%$ to $7 \%$ ) of the patients in the current study.

Similar to illicit drugs, prescriptioncontrolled substances are not only used, but also abused widely. Various reasons attributed to their widespread use are relaxed public perception of the harm, pop- 
ularization by the media and by advocacy groups, easy accessibility of the drugs through the internet, easy accessibility of controlled substances through multiple busy practices, and easy availability of controlled substances on the street. Drug abuse is associated with impaired education, impaired productivity, and criminal behavior. The use of controlled substances produces not only pain relief and anxiolysis, but also feelings of relaxation and well being. Overdoses of opioids, specifically methadone, has been disastrous. Symptoms of withdrawal from controlled substances include restlessness, irritability, and insomnia.

The study may be criticized for utilizing rapid drug screening instead of gas chromatography/mass spectroscopy (GC/MS), or enzyme immunoassay. Further, the study may be criticized for having only 100 patients and not correlating multiple variables with drug abuse or illicit drug use.

First, rapid drug screening utilizing enzyme immunoassay has been shown to be valid. It is a reliable screening tool for multiple drugs, rapidly and inexpensively. A side-by-side comparison of rapid drug testing with GC/MS yielded over $90 \%$ correlation. Agreement with GC/MS was $91 \%$ for THC, $93 \%$ for cocaine, over $96 \%$ for methadone, over $95 \%$ for opioids, 96\% for amphetamines and methamphetamines, and 99\% for barbiturates. Thus, we assume that the results are reasonably accurate. However, we advise that physicians should exercise caution if the patient is denied future treatment based on these results. In such cases, results should be accurately confirmed with laboratory testing utilizing GC/MS.

Second, criticism may be forwarded that we used only 100 patients. In an interventional pain management settings, 100 patients represent a significant proportion for one physician's practice.

Third, the authors realize that the correlation between a multitude of variables was not established. To establish appropriate correlations, it would be necessary to study as many as 1,200 patients based on various statistical methods; this may be the subject of future study.

The results of this evaluation showed that illicit drug use and misuse of prescription opioids are common in chronic pain patients presenting for initial evaluation. Appropriate history and urine toxicology provides significant insight into il- licit drug use and possible controlled substance abuse.

\section{Conclusion}

Evaluation of 100 patients presenting to an interventional pain management practice showed that patients suffered with an average of 9.3 years of pain, involving multiple body regions, were treated by numerous providers, the majority were disabled, and $90 \%$ used opioids. A significant proportion of patients inappropriately reported opioid use, either underuse or overuse, with 23 patients using illicit drugs, and 12 non-prescription opioids. Thirty-five of 100 patients seen initially were exhibiting one of the abuse behaviors. In addition, an additional 42 patients prescribed opioids failed to show opioids in their urine. A significant proportion of patients were also suffering with anxiety, depression, and somatization.

\section{Author Affiliation: \\ Laxmaiah Manchikanti, MD \\ Medical Director \\ Pain Management Center of \\ Paducah \\ Assistant Clinical Professor of \\ Anesthesiology and Perioperative \\ Medicine \\ University of Louisville, KY \\ 2831 Lone Oak Road \\ Paducah, Kentucky 42003 \\ E-mail:drm@apex.net}

\section{Kim S. Damron, RN}

Nursing Administrator

Ambulatory Surgery Center

2831 Lone Oak Road

Paducah, Kentucky 42003

E-mail: kim@thepainmd.com

Carla D. McManus, RN, BSN

Assistant Nursing Administrator

Ambulatory Surgery Center

2831 Lone Oak Road

Paducah, Kentucky 42003

E-mail: carla@thepainmd.com

Renee C. Barnhill, RN

Clinical Coordinator

Ambulatory Surgery Center

2831 Lone Oak Road

Paducah, Kentucky 42003

E-mail: Renee@thepainmd.com

\section{RefERENCES}

1. Verhaak PFM, Kerssens JJ, Dekker J et al. Prevalence of chronic benign pain disorder among adults: A review of the literature. Pain 1998; 77:231-239.

2. Van Den Kerkhof EG, Hopman WM, Towheed TE et al. The impact of sampling and measurement on the prevalence of self-reported pain in Canada. Pain Res Manage 2003; 8:157-163.

3. Moulin DE, Clark AJ, Speechley M et al. Chronic pain in Canada - prevalence, treatment, impact and the role of opioid analgesia. Pain Res Manage 2002; 7:179184.

4. Elliott AM, Smith BH, Hannaford PC et al. The course of chronic pain in the community: Results of a 4-year follow-up study. Pain 2002; 99:299-307.

5. Yeung SS, Genaidy A, Deddens I et al. Prevalence of musculoskeletal symptoms in single and multiple body regions and effects of perceived risk of injury among manual handling workers. Spine 2002; 27:2166-2172.

6. Andersson $\mathrm{HI}$, Ejlertsson $\mathrm{G}$, Leden I et al. Chronic pain in a geographically defined general population: Studies of differences in age, gender, social class, and pain localization. Clin J Pain 1993; 9:174-182.

7. Ferrell BR, Ferrell BA (eds). Pain in the elderly. A report of the task force on pain in the elderly of the international association for the study of pain. IASP Press, Seattle, 1996.

8. Cassidy D, Carroll L, Cotê P: The Saskatchewan Health and Back Pain Survey. The prevalence of low back pain and related disability in Saskatchewan Adults. Spine 1998; 23:1860-1867.

9. Côté DC, Cassidy JD, Carroll L. The Saskatchewan Health and Back Pain Survey. The prevalence of neck pain and related disability in Saskatchewan adults. Spine 1998; 23:1689-1698.

10. Lawrence RC, Helmick CG, Arnett FC. Estimates of the prevalence of arthritis and selected musculoskeletal disorders in the United States. Arthritis Rheum 1998; 41: 778-799.

11. American Pain Society. Principles of analgesic use in the treatment of acute pain and cancer pain, $4^{\text {th }}$ edition. American Pain Society, Glenview, 1999.

12. Joranson DE, Carrow GM, Ryan KM et al. Pain management and prescription monitoring. J Pain Symptom Manage 2002; 23: 231-238.

13. American Medical Association. Curtailing prescription drug abuse while preserving therapeutic use: American Medical Association recommendations for drug control policy. In: Wilford BB, ed. Balancing the Response to Prescription Drug Abuse, Chicago, American Medical Association, 1990, pp 273-298.

14. Chou R, Clark E, Helfand M. Comparative efficacy and safety of long-acting oral opi- 
oids for chronic non-cancer pain: A systematic review. J Pain Symptom Manage 2003; 26:1026-1048.

15. Luo X; Pietrobon R, Hey L. Patterns and trends in opioid use among individuals with back pain in the United States. Spine 2004; 29:884-891.

16. Turk DC. Clinical effectiveness and costeffectiveness of treatments for patients with chronic pain. Clin J Pain 2002; 18: 355-365.

17. Turk DC, Brody MC, Okifuji EA. Physicians' attitudes and practices regarding the longterm prescribing of opioids for non-cancer pain. Pain 1994; 59:201-208.

18. Fishbain DA, Rosomoff $\mathrm{HL}$, Rosomoff RS. Drug abuse, dependence, and addiction in chronic pain patients. Clin J Pain 1992; 8: 77-85.

19. Chabal C, Erjavec MK, Jacobson L et al. Prescription opiate abuse in chronic pain patients: Clinical criteria, incidence, and predictors. Clin J Pain 1997; 13:150-155.

20. Atluri S, Sudarshan G. Evaluation of abnormal urine drug screens among patients with chronic non-malignant pain treated with opioids. Pain Physician 2003; 6:407409.

21. Katz NP, Sherburne S, Beach M et al. Behavioral monitoring and urine toxicology testing in patients receiving long-term opioid therapy. Anesth Analg 2003; 97:10971102.

22. Manchikanti L, Pampati V, Damron K et al. Prevalence of illicit drug use in patients without controlled substance abuse in interventional pain management. Pain Physician 2003; 6:173-178.

23. Manchikanti L, Pampati V, Damron K et al. Prevalence of opioid abuse in interventional pain medicine practice settings: A randomized clinical evaluation. Pain Physician 2001; 4:358-365.

24. Manchikanti L, Pampati V, Damron K. Prevalence of prescription drug abuse and dependency in patients with chronic pain in western Kentucky. J KY Med Assoc 2003; 101:511-517.

25. Manchikanti L, Beyer C, Damron K et al. A comparative evaluation of illicit drug use in patients with or without controlled substance abuse in interventional pain management. Pain Physician 2003; 6:281285.

26. Fishman SM, Wilsey B, Yang J et al. Adherence monitoring and drug surveillance in chronic opioid therapy. J Pain Symptom Manage 2000; 20:293-307.

27. Gajraj N, Hervias-Sanz M. Opiate abuse or undertreatment? Clin J Pain 1998; 14:9091.

28. Prescription Drug Monitoring: Strategies to Promote Treatment and Deter Prescription Drug Abuse. Hearings of Subcommittee on Health House Energy and Commerce Committee, March 4, 2004.

29. Substance Abuse and Mental Health Services Administration, Office of Applied Studies. National Survey of Substance Abuse Treatment Services (N-SSATS): 2002. Data on Substance Abuse Treatment Facilities, DASIS Series: S-19, DHHS Publication No. (SMA) 03-3777, Rockville, MD, 2003.

30. Atluri S, Boswell M, Hansen $\mathrm{H}$ et al. Guidelines for the use of controlled substances in the management of chronic pain. Pain Physician 2003; 6:233-257.

31. Manchikanti L, Singh V, Damron KS et al. Screening for controlled substance abuse in interventional pain management settings: Evaluation of an assessment tool. Pain Physician 2003; 6:425-433.

32. Manchikanti L, Pampati V, Damron KS et al. Evaluation of variables in illicit drug use: Does a controlled substance abuse screening tool identify illicit drug use? Pain Physician 2004; 7:71-76.

33. Savage SR. Assessment for addiction in pain-treatment settings. Clin I Pain 2002; 18:S28-S38.

34. Kirsh KL, Whitcomb LA, Donaghy K et al. Abuse and addiction in medically ill patients with pain: Attempts at clarification of terms and empirical study. Clin J Pain 2002; 18S52-S60.

35. Compton P, Darakjian J, Miotto K. Screening for addiction in patients with chronic pain and "problematic" substance use: Evaluation of a pilot assessment tool. Pain Symptom Manage 1998; 16:355-363.

36. Robinson RC, Gatchel RJ, Polatin P et al. Screening for problematic prescription opioid use. Clin J Pain 2001; 17:220-228.

37. Chabal C, Jacobson L, Mariano A et al. Narcotics for chronic pain? Yes or no. A useless dichotomy. Am Pain Soc J 1992; 1: 276-281.

38. Chabal C, Jacobson L, Mariano A et al. The psychosocial impact of opioid treatment. Am Pain Soc J 1992; 1:289-291.

39. Chabal C, Jacobson L, Mairano AJ et al. Pseudoaddiction or pseudo label? Clin J Pain 1998; 14:90-91.

40. Manchikanti L, Fellows B. Psychological screening in low back pain. In Manchikanti L, Slipman CW, Fellows B (eds), Interventional Pain Management: Low Back Pain - Diagnosis and Treatment. ASIPP Publishing, Paducah, KY 2002; 167176.

41. Tollison CD, Langley JC. Pain Patient Profile (P-3) Manual. National Computer Systems, Minneapolis, 1995.
42. Compton WM, Grant BJ, Colliver JD et al. Prevalence of Marijuana Use Disorders in the United States: 1991-1992 and 20012002. JAMA 2004; 291:2114-2121.

43. Johnston LD, O'Malley PM, Bachman JG. Monitoring the Future National Survey Results on Drug Use, 1975-2002. Bethesda, Md: National Institute on Drug Abuse; 2003.

44. Lynskey M, Hall W. The effects of adolescent cannabis use on educational attainment: a review. Addiction 2000;95:16211630.

45. Lehman WE, Simpson DD. Employee substance abuse and on-the-job behaviors. J Appl Psychol 1992;77:309-321.

46. Lynskey MT, Health AC, Bucholz KK, et al. Escalation of drug use in early onset cannabis users vs co-twin controls. JAMA 2003;289:427-433.

47. National Highway Traffic Safety Administration. Traffic Safety Facts 2001. Washington, DC: National Highway Traffic Safety Administration; 2001.

48. Mittleman MA, Lewis RA, Maclure M, Sherwood JB, Muller JE. Triggering myocardial infarction by marijuana. Circulation 2001;103:2805-2809.

49. Tashkin DP. Pulmonary complications of smoked substance abuse. West J Med 1990;152:525-530.

50. Cami J, Farré M. Mechanisms of Disease: Drug addiction. NEJM 2003; 349:975986.

51. Hall W, Solowij N. Adverse effects of cannabis. Lancet 1998;352:1611-1616.

52. Budney AJ, Hughes JR, Moore BA et al. Marijuana abstinence effects in marijuana smokers maintained in their home environment. Arch Gen Psychiatry 2001;58: 917-924.

53. Office of National Drug Control Policy, Drug Facts: Cocaine, May 2002.

54. Sarnyai Z, Shaham Y, Heinrichs SC. The role of corticotropin-releasing factor in drug addiction. Pharmacol Rev 2001;53: 209-243.

55. Farre M, de la Torre R, Gonzalez ML et al. Cocaine and alcohol interactions in humans: neuroendocrine effects and cocaethylene metabolism. J Pharmacol Exp Ther 1997;283:164-176.

56. Mello NK, Mendelson JH. Cocaine's effects on neuroendocrine systems: clinical and preclinical studies. Pharmacol Biochem Behav 1997;57:571-599.

57. Mendelson JH, Mello NK. Management of cocaine abuse and dependence. $N$ Engl J Med 1996; 334:965-972. 
